\title{
Utilization of abrasive water jet for cutting parts of intricate shapes
}

\author{
Safwan M. A. Al-Qawabah ${ }^{1}$, Adnan I. O. Zaid ${ }^{2}$ and Nasser Abdellatif ${ }^{3}$ \\ ${ }^{1}$ Mechanical Engineering Department, Tafila Technical University, Amman, Jordan \\ ${ }^{2,3}$ Mechanical and Industrial Engineering Department, Applied Science University, Amman, Jordan
}

\begin{abstract}
As early as 1974 the British Hydrodynamic Research Association, BHRA, held the First International Conference on Cutting by Water Jets. The subject was at its early stages. Since then a large amount of research work has been carried out and the process has been greatly developed. In this paper, utilization of water jets for flexible cutting parts of intricate shapes in steel plates and granite is presented and discussed.
\end{abstract}

\section{Introduction}

The abrasive water jet (AWJ) cutting technique is one the most rapidly improving technological methods of cutting materials. In this cutting technique, a thin, high velocity water jet accelerates abrasive particles that are directed through an abrasive water jet nozzle at the material to be cut. Advantages of abrasive water jet cutting include the ability to cut almost all materials, no thermal distortion, and high flexibility, small cutting forces and being environmentally friendly. Because of these capabilities, this cutting technique is more cost-effective than traditional and some non-traditional machining processes [1]. The surface roughness is mainly a result of various controllable or uncontrollable process parameters and it is harder to attain and track than physical dimensions are. A considerable number of studies have researched the effects of the feed rate, standoff distance, water pressure, abrasive grain size, and other factors on the surface roughness [2, 3, 4]. Experimental measurements of vibrations and acoustic emissions accompanying AWJ cutting were conducted and their results investigated indepth by Hloch et al. [5, 6] to provide a practical method of monitoring the process and predicting surface roughness. It is a well-established and recognized fact that the developments which underlie our present civilization e.g. the modern cars, locomotives, electrical trains, space crafts and modern house ware which we rely for our pleasure and livelihood have been made possible largely by the continued improvement in the surface quality of the produced parts by various casting, forming and machining processes. Accurate manufacturing and the production of near net shape parts of closely mating parts or duplicate parts to small dimensional limits with small tolerances is inseparably bound with high qualitymachined surfaces. Any effort to advance in the field of surface quality, however, leads inevitably to study the nature of the produced surface, its surface roughness and metallurgical structure. Hence, we have experienced in recent years outstanding developments in producing and measuring means for economic attainment of high quality produced surfaces. In this paper, six parts of intricate shapes, (five are made of mild steel and one made of granite) were produced by cutting with water jet. The surface roughness at the edges of the produced parts aremeasured and the obtained results are presented and discussed. Furthermore, the Vickers micro-hardness at their edges and at different distances were determined and discussed. Finally, the advantages of this method as compared with flame cutting and high explosive shaped charges are discussed.

\section{Materials and experimental procedures}

\subsection{Materials}

Two materials were used one ductile, ASTM A36 mild steel of the chemical composition shown in Table 1; from which parts A, B, C, D and E, were produced, Fig. 2 and a brittle material, granite, part $\mathrm{F}$ in Fig. 2.

Table 1. Chemical composition of ASTM A36 mild steel

\begin{tabular}{|c|c|c|c|c|c|c|c|}
\hline Element & $\mathrm{C}$ & $\mathrm{Cu}$ & $\mathrm{Fe}$ & $\mathrm{Mn}$ & $\mathrm{P}$ & $\mathrm{Si}$ & $\mathrm{S}$ \\
\hline Wt.\% & $\begin{array}{l}0.25- \\
0.29\end{array}$ & 0.2 & 98.0 & 1.03 & 0.04 & 0.28 & 0.05 \\
\hline
\end{tabular}

\subsection{Equipment}

An abrasive water jet machine type (CMS EASYLINE 7785), shown in Fig. 1 was used for cutting six parts of intricate shapes four of them are made of ductile material, mild steel, A, B, C, D and E of the mechanical behavior shown in Table 1; and one is made of brittle material, granite, F. They are all shown in Fig. 2.

The microhardness test was performed using Microhardness machine tester model HWDM-3, where 
the average surface roughness ( $\mathrm{Ra}$ ) measurement was based on cut off distance $=0.8$ and ISO $13565(\mathrm{Rk})$, after each cutting test using surface tester type (kosaka surfcorder SE3500).

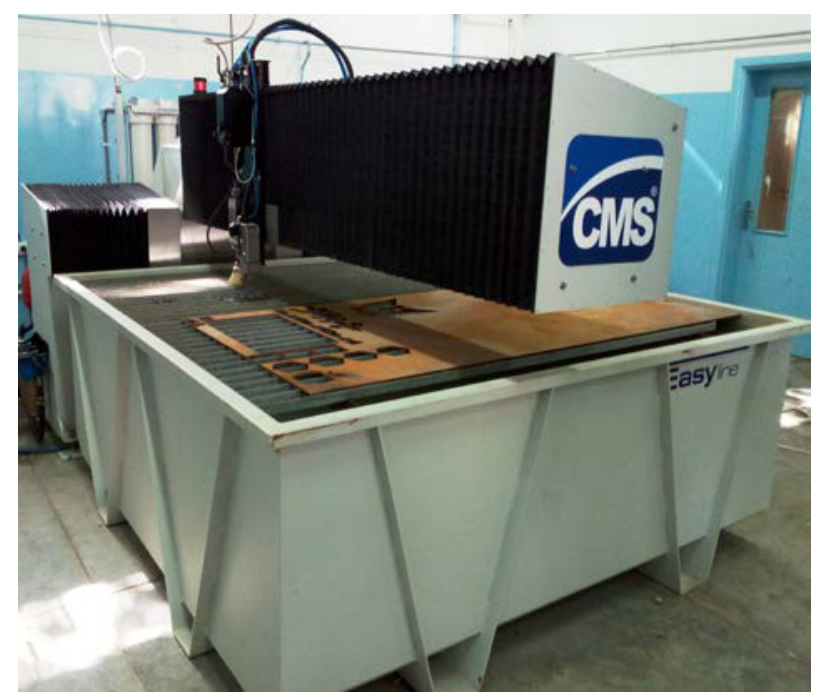

Figure 1. Abrasive water jet machine type (CMS EASYLINE 7785).
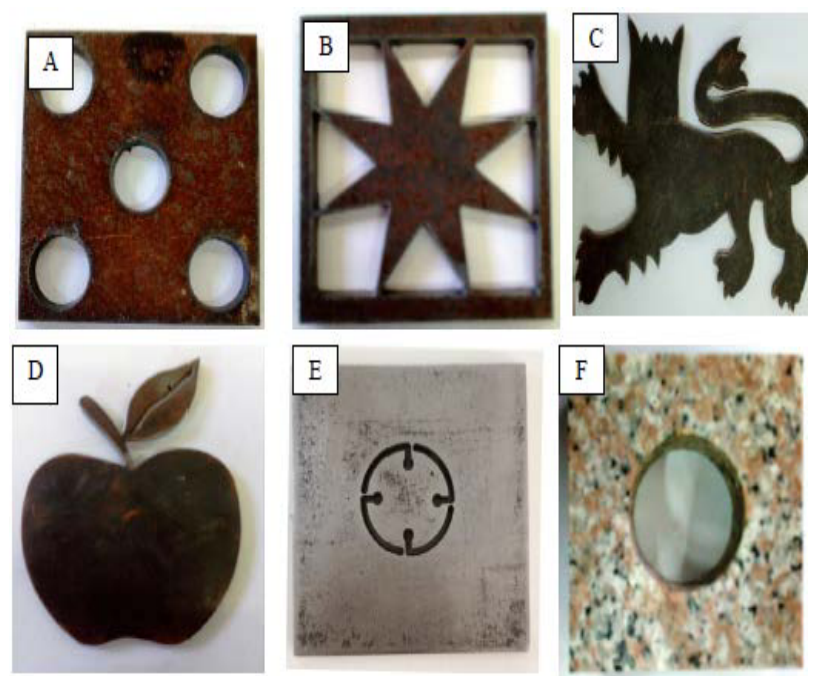

Figure 2. Flexible shapes, (A, B, C, D, and E) are made from mild steel and $(\mathrm{F})$ is made from granite which were machined using the abrasive $\mathrm{CNC}$ water jet machine.

\subsection{Experimental procedures}

The experimental procedure started by adjusting the abrasive water jet machine to the working conditions defined in Table 2, followed by placing the work piece, the plate, and fixing it in position, preparing the abrasive water jet, adjust the CNC program, CREW software, and finally start the machine at the working conditions specified in Table 2 .

\section{Results and discussion}

In this section, The surface roughness of the six produced parts was measured at five different locations on each part, Table 3, from which the average RMS was determined, the obtained results are presented, discussed and compared with values reported in the literature for different machining processes including finishing and super finishing processes, Table 4.

\subsection{Comparison between surface quality of parts produced by Abrasive water jet and other Methods}

Table 4 shows the values of the average applied values of surface roughness, $\mathrm{Ra}$, and the less frequent produced by different machining processes, included for comparison purposes. It can be seen from Tables 3 and 4 that the surface quality of the intricate parts produced by abrasive water jets is comparable to the average applied surface quality produced obtained from chemical machining, CM, and electric discharge machining, EDM and better than other machining process illustrated in Table 4. Furthermore, it can also be observed in Table 3 that the parts of intricate shapes which are geometrically similar around the horizontal and vertical center lines produced better surface quality than the other parts as $\mathrm{Ra}$ (av.) falls between $1.92 \mu \mathrm{m}$ and $2.24 \mu \mathrm{m}$ for the first and between $4.08 \mu \mathrm{m}$ and $4.65 \mu \mathrm{m}$ for the latter respectively.

Table 3. Average surface roughness of the different produced parts by water jets.

\begin{tabular}{|l|c|l|l|l|l|l|l|}
\hline Shapes & $\mathrm{R}_{\mathrm{a}}$ & $\mathrm{R}_{\mathrm{a}}$ & $\mathrm{R}_{\mathrm{a}}$ & $\mathrm{R}_{\mathrm{a}}$ & $\mathrm{R}_{\mathrm{a}}$ & $\begin{array}{l}\mathrm{Ra} \\
(\mu \mathrm{mm})\end{array}$ & $\begin{array}{l}\mathrm{Ra} \\
(\mu \mathrm{in})\end{array}$ \\
\hline $\mathrm{A}$ & 1.79 & 1.97 & 2.0 & 2.03 & 1.81 & 1.92 & 75.59 \\
\hline $\mathrm{B}$ & 1.86 & 2.16 & 1.8 & 2.1 & 1.95 & 1.98 & 77.95 \\
\hline $\mathrm{C}$ & 3.90 & 3.3 & 4.6 & 4.4 & 4.20 & 4.08 & 160.63 \\
\hline $\mathrm{D}$ & 3.82 & 4.80 & 4.36 & 4.91 & 4.13 & 4.40 & 173.23 \\
\hline E & 4.22 & 4.65 & 4.28 & 4.97 & 5.30 & 4.65 & 183.07 \\
\hline $\mathrm{F}$ (granite) & 2.65 & 2.06 & 2.38 & 2.22 & 2.41 & 2.24 & 88.19 \\
\hline
\end{tabular}

Table 2. Constant parameters and their values

\begin{tabular}{|c|c|c|c|c|c|c|}
\hline $\begin{array}{l}\text { Constant } \\
\text { parameters }\end{array}$ & $\begin{array}{l}\text { Orifice diameter } \\
\qquad(\mathrm{mm})\end{array}$ & $\begin{array}{l}\text { Focusing tube } \\
\text { diameter } \\
(\mathrm{mm})\end{array}$ & $\begin{array}{l}\text { Water jet pressure } \\
\qquad(\mathrm{MPa})\end{array}$ & Abrasive type & $\begin{array}{l}\text { Abrasive size (grit } \\
\text { no) }\end{array}$ & $\mathrm{SOD}(\mathrm{mm})$ \\
\hline Value & 0.25 & 0.762 & 200 & $\begin{array}{c}\text { GMT } \\
\left(\mathrm{TiO}_{2}\right)\end{array}$ & $\begin{array}{c}80 \mathrm{mesh} \\
(200 \mathrm{gr} / \mathrm{min}) \text { Size: } 5 \\
\mu \mathrm{m}, \rho=5 \mathrm{mg} / \mathrm{m}^{3}\end{array}$ & 2 \\
\hline
\end{tabular}


Table 4. The average applied frequent methods of different machining processes [7]

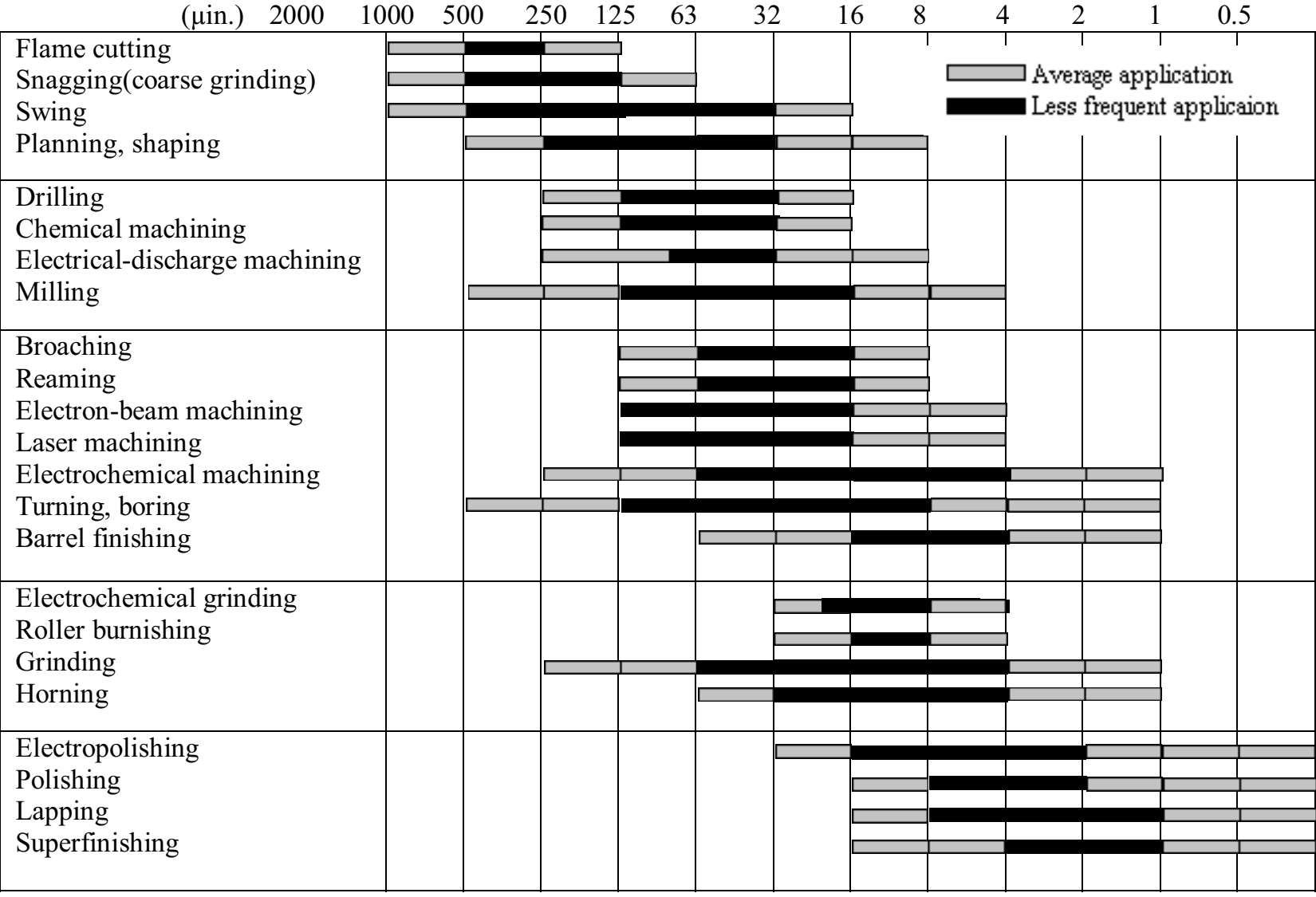

\subsection{Advantages of cutting by abrasive water jets}

The following are its advantages over other cutting processes:

i. Very good surface quality can be obtained of the produced parts; better than some other cutting (material removal processes) e.g. flame cutting, oxyacetylene cutting and cutting by high explosive charges.

ii. Very little or no material loss as chips.

iii. It produces parts effectively from both ductile and brittle materials.

iv. It is capable of producing parts of intricate shapes with very small tolerances which is almost like the original part.

v. It does not require highly qualified technicians like the other machining processes e.g. turning, milling, shaping, grinding.

vi. Although its capital cost is higher than some other machining processes, it is outweighed by the the operational low cost, hence it can be considered economical process.

vii. Little or no temperature rise in the produced parts or the remaining parent part due to the low pressure of the jet; hence no metallurgical changes are expected to take place in any of them. viii. Wide range of sizes, weights and shapes of different materials. Thickness up to $222 \mathrm{~mm}$

ix. Less precautions and no preparation of the machined parts are required as compared with other cutting and machining processes.

\subsection{Effect of cutting by abrasive water on vickers micro-hardness}

To investigate the effect of cutting by the abrasive water jet on the hardness, the produced parts were sectioned across their geometrical center lines and the Vickers microhardness was measured at seven locations at the edges of the cut and at equal distances of I mm away from it, from which the average microhardness was determined and the results are presented in Fig. 3a) and b) for mild steel and granite respectively. It can be seen from these two figures that very slight variation in their Vickers microhardness has taken place with a maximum increase of $1.23 \%$ and of $1.8 \%$ decrease in the mild steel work pieces and retained their original hardness after 5 $\mathrm{mm}$ from the cutting edge. Regarding the granite work piece no drop in its microhardness was observed and the increase in it varied between maximum increase of $2.59 \%$ and $2.81 \%$. These values are much smaller than the increase in cutting by other cutting means like oxyacetylene, plasma, laser or high explosive shaped charges where more than $25 \%$ has taken place [8]. 


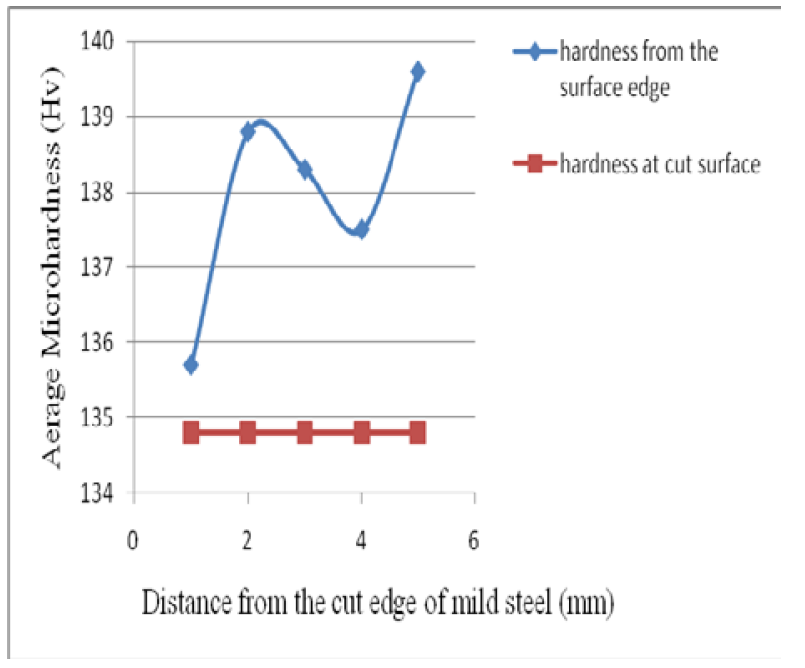

a) Mild steel

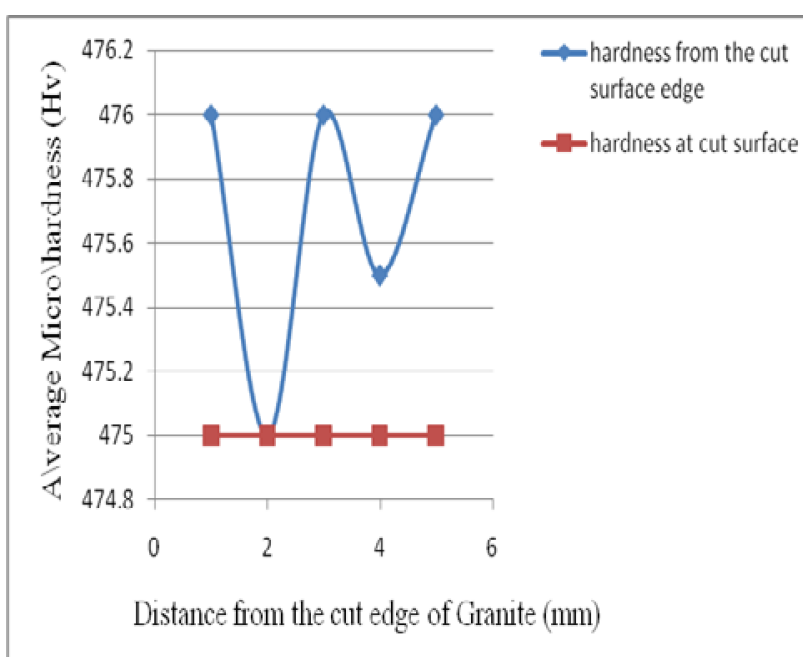

b) Granite

Figure 3. Variation of the Vickers micro-hardness at the edge of the cut and a distance from it.

\section{Conclusions}

Based on this research work and within its limitations; the following points are concluded:

i) The abrasive $\mathrm{CNC}$ water jet can produce net intricate shapes with small tolerances and very high surface quality comparable to the super finishing processes. The maximum average RMS of the produced parts is $4.65 \mu \mathrm{m}$ and the minimum average value is 1.98 $\mu \mathrm{m}$.

ii) Slight increase in the Vickers microhardness, HV, at the edges of the produced parts but it retains its original hardness at $5 \mathrm{~mm}$ from the cutting edge.

iii) Little or no temperature rise in the produced parts or the remaining parent part due to the low pressure of the jet; hence no metallurgical changes are expected to take place in any of them.

iv) Cutting with abrasive $\mathrm{CNC}$ water jet may be considered economical process although the capital investment is relatively high compared with other machining means. However, it is outweighed by the low operating costs.

\section{Acknowledgement}

The first author would like to express his thanks to technician Amer Amayerah and to Tafila Technical University support.

\section{References}

1. D. Krajcarz: Comparison metal water jet cutting with laser and plasma cutting, ( Proceeding of 24th DAAAM International Symposium on Intelligent Manufacturing and Automation, Procedia Engineering 69, 2014) p. 838-843.

2. R. Kovacevic: Surface texture in abrasive water jet cutting Journal of Manufacturing System Vol. 10 (1991), p, 32-40.

3. A. Akkurt, M.K. Kulekci, U. Seker and F. Ercan: Effect of feed rate on surface roughness in abrasive water jet cutting applications, Journal of Materials Processing Technology Vol. 147 (2004), p. 389-396.

4. D.A. Axinte, D.S. Srinivasu, M.C. Kong and P.W. Butler-Smith: Abrasive water jet cutting of polycrystalline diamond; A preliminary investigation, International Journal of Machine Tools \& Manufacture Vol. 49 (2009), p.797-803.

5. D. Kinik, B. Ganovska, S. Hloch, P. Monka, K. Monkova, and Z. Hutyrova: On-line monitoring of technological process of material abrasive water jet cutting. Tehnički vjesnik Vol. 22 (2015), p. 351-357.

6. P. Hreha, S. Hloch and V. Perzel: Analysis of acoustic emission recorded during monitoring of abrasive water jet cutting of stainless steel AISI 309. Tehnički vjesnik Vol.19 (2012), p.355-359.

7. S. Kalpakjian, S.R.Schmid: Manufacturing Processes for Engineering Materials, $4^{\text {th }}$ Edition, Prentice Hall Publishers, (2003).

8. A.I.Zaid, Cutting plates by high explosive shaped charges, M.Sc. Dissertation, UMIST, (1971). 